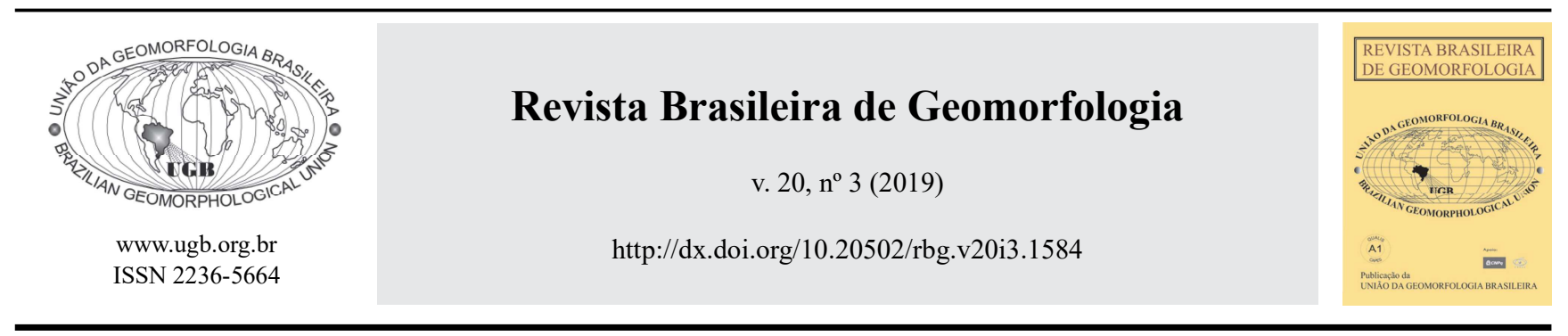

\title{
A INFLUÊNCIA DOS MATERIAIS DAS MARGENS E DA VEGETAÇÃO CILIAR NA EROSÃO DE MEANDROS: O CASO DO RIO CLARO, AFLUENTE DO RIO ARAGUAIA
}

\author{
THE INFLUENCE OF RIVER BANK MATERIAL AND RIPARIAN \\ VEGETATION ON MEANDER EROSION: STUDY CASE OF THE CLARO \\ RIVER, TRIBUTARY OF THE ARAGUAIA RIVER
}

Wallas de Souza Castro

Terral Energia

Al. Ricardo Paranhos, 619, Marista, Goiânia. Goiás. CEP 74175-020. Brasil

ORCID: 0000-0000-0000-0000

E-mail:wallascastro2@gmail.com

Alfredo Borges de Campos

Instituto de Geociências, Universidade Estadual de Campinas

R. Carlos Gomes, 250, Campinas, São Paulo. CEP: 13083-851. Brasil

ORCID: 0000-0000-0000-0000

E-mail:acampos@ige.unicamp.br

\begin{abstract}
Márcio Henrique de Campos Zancopé
Instituto de Estudos Socioambientais, Universidade Federal de Goiás

Av. Esperança, s/n - Samambaia, Goiânia, Goiânia. CEP: 74001-970. Brasil
\end{abstract}

ORCID: 0000-0000-0000-0000

E-mail: zancope@ufg.br

\section{Informações sobre o Artigo}

Recebido (Received):

20/04/2019

Aceito (Accepted):

08/06/2019

\section{Palavras-chave:}

Erosão Marginal; Migração

Lateral; Estabilidade Geotécnica de Leitos Aluviais.

\section{Keywords:}

Bank Erosion; Lateral Migration; Geotechnical Stability of Alluvial Beds

\section{Resumo:}

A erosão sobre as margens côncavas é um processo intrínseco à migração lateral de meandros. A hidráulica da corrente fluvial e os materiais constituintes das margens influenciam as taxas de erosão e migração lateral. O objetivo deste artigo é verificar a correlação entre as taxas de erosão marginal de dois meandros do baixo curso do Rio Claro, afluente do Rio Araguaia, Centro-Oeste do Brasil, e a natureza dos materiais constituintes das margens côncavas (variação faciológica e desagregação espontânea - estabilidade geotécnica) e a vegetação ciliar presente e ausente. As taxas de erosão foram determinadas pelo monitoramento (2013-2014) de pinos de erosão instalados ao longo das margens côncavas, enquanto que os materiais constituintes foram caracterizados pela descrição faciológica das margens e análises laboratoriais para determinação granulométrica e desagregação espontânea de amostras em submersão aquosa. Os resultados mostraram elevadas taxas de erosão das margens côncavas dos meandros (entre $67 \mathrm{~cm}$ e $120 \mathrm{~cm}$ ), concentradas próximas ao eixo dos meandros, bem como nas porções das margens constituídas por areia média e grossa e resposta mais rápida a desagregação sob submersão. As margens com vegetação ciliar presente não apresentaram taxas de erosão menor que as margens desmatadas, 
sugerindo que a vegetação ciliar contribui pouco para frear a erosão marginal e migração lateral de sistemas fluviais meandrantes similares ao Rio Claro.

\begin{abstract}
:
Erosion on concave streambanks is an intrinsic process to lateral migration of river meanders. Hydraulics of fluvial currents and nature of materials present in the streambanks influence the rates of bank erosion and stream lateral migration. This paper aims at verifying the correlation between concave streambank erosion rates of two meanders located at the lower course of the Claro River, tributary of the Araguaia River, Central Brazil, the nature of materials present at concave streambanks (faciological variation and spontaneous disaggregation - geotechnical stability) and existing or absent riparian vegetation. Streambank erosion rates were determined by monitoring (2013-2014) pins set along concave streambanks whereas concave streambanks materials were characterized by faciological description in the field and laboratory analysis for determination of granulometric classes and spontaneous material disaggregation under aqueous submersion. Results showed high erosion rates of concave streambanks of the meanders (between $67 \mathrm{~cm}$ and $120 \mathrm{~cm}$ ) concentrated close to the axis of the meanders, as well as in portions of river streambanks consisting by medium and coarse sand with faster disaggregation under aqueous submersion. Concave streambanks with riparian vegetation did not show erosion rates lower than those deforested, suggesting the riparian vegetation contributes little to stop streambank erosion and lateral migration of meanders of fluvial systems that are similar to those of the Claro River.
\end{abstract}

\section{Introdução}

Um canal fluvial pode apresentar distintos padrões morfológicos, desenvolvendo trechos retilíneos, meandrantes e entrelaçados/anastomosados (LEOPOLD; WOLMAN, 1970; SCHUMM, 1981), bem como apresentar formas transicionais entre cada padrão. No caso dos rios meandrantes, a principal característica é a alta sinuosidade, seguido pela notável migração lateral do canal fluvial. Segundo Derruau (p.100, 1966), em canais meandrantes, "a margem côncava se escava (por erosão) cada vez mais, enquanto na margem convexa a corrente é lenta e abandona parte da carga sedimentar, construindo uma barra aluvial". Segundo o mesmo autor é com esta dinâmica que a sinuosidade do canal aumenta (DERRUAU, 1966).

Devido a sua dinâmica intrínseca, os canais meandrantes são considerados um dos principais agentes responsáveis pelo desenvolvimento das planícies fluviais (NANSON e CROKE, 1992), especialmente devido aos processos de migração lateral. Ollero (2010) identificou processos de migração lateral como corte de meandros (chute e neck cutoff), expansão (crescimento do raio de curvatura) e rotação de meandros (giro do eixo de curvatura) em virtude da mobilidade do rio Ebro (Espanha). Huhmann et al. (2004) explicaram a evolução quaternária da planície do Rio Dnister superior (Ucrânia) por migrações sucessivas dos meandros. Similarmente, estudando a formação de morfologias de planícies fluviais, Constantine e Dunne (2008) observaram a frequência dos processos de cortes de meandros (chute e neck cutoff), associando-os ao desenvolvimentos de lagos de meandros (oxbow lakes) em rios da Rússa, Colômbia e Nova Guiné.
Por se tratar de um sistema aberto, a migração lateral dos rios meândricos é influenciada por diversos elementos da paisagem. Corney et al. (2006), por exemplo, mostraram a influência da natureza da corrente fluvial ao indicar que a dinâmica migratória é especialmente resultante das propriedades hidráulicas dos fluxos helicoidais inerentes aos canais meandrantes. Similarmente, Aquino et al. (2008) e Valente et al. (2013) associam a dinâmica processual dos meandros às variações das descargas fluviais.

Ao migrar lateralmente, o rio meandrante produz erosão na margem côncava da curva do meandro e deposição na margem convexa. Muito embora a dinâmica de migração lateral dos meandros possua fatores hidráulicos e climáticos envolvidos, a vegetação ciliar também é abordada como influência potencial na dinâmica migratória dos meandros. A presença da vegetação ciliar torna as margens menos erodíveis e reduzem a quantidade de material depositado a jusante (CASCO et al., 2005). Perucca et al (2007) e Micheli et al. (2004) observaram que a vegetação pode induzir maiores ou menores taxas de erosão marginal (bank erosion), influenciando assim a evolução temporal das curvas de meandros.

Além do possível controle exercido na atenuação da erosão das margens de rios meandrantes pela vegetação ciliar, a interdigitação entre depósitos argilosos, arenosos e cascalhentos, coesos e incoesos, muito ou pouco pedogenizados, distribuídos no interior das planícies aluviais, também influenciam a migração lateral dos meandros. Quando se trata da variação de erosão marginal, os materiais constituintes das margens dos 
meandros são elementos intrísecos aos processos de migração lateral. Hickin e Nanson (1975) observaram associações de processos migratórios de curvas meândricas em função do ajustamento do tipo de carga detrítica, do fluxo e do material constituinte do leito e das margens. Constantine, et al. (2009) verificaram que o coeficiente de erosão marginal de meandros depende das propriedades físicas dos materiais constituintes das margens. Enquanto Hooke (1980) identificou a variação de erosão marginal em virtude dos materiais constituintes da planície do rio Devon (Reino Unido), Souza e Cunha (2007) observaram o mesmo para rio Paraguai.

Este artigo procura contribuir com a discussão da influência da vegetação ciliar e dos materiais constituintes das margens sobre a migração lateral de rios meandrantes. Tem como objetivo específico verificar a correlação existente entre as taxas de erosão marginal de duas curvas do baixo curso do rio Claro, no oeste do estado de Goiás, a presença e a ausência da mata ciliar, a variação faciológica lateral e a distinta desagregação espontânea sob condições saturadas dos materiais constituintes das margens. As curvas estudadas do baixo rio Claro estão inseridas em ampla planície aluvial, em trecho com padrão de canal meandrante de mobilidade lateral elevada por uma diversidade de processos de migração, constadado por Castro et al. (2014).

\section{2. Área de Estudo}

Foram selecionadas as margens côncavas de duas curvas meândricas localizadas no baixo curso do Rio Claro, afluente da margem direita do Rio Araguaia (Figura 1). O sistema fluvial do Rio Claro drena área aproximada de $10.276 \mathrm{~km}^{2}$. A bacia do rio Claro apresenta altitudes entre $250 \mathrm{~m}$ e $1000 \mathrm{~m}$. No quadro 1 apresenta-se as características morfométricas da bacia hidrográfica do Rio Claro.

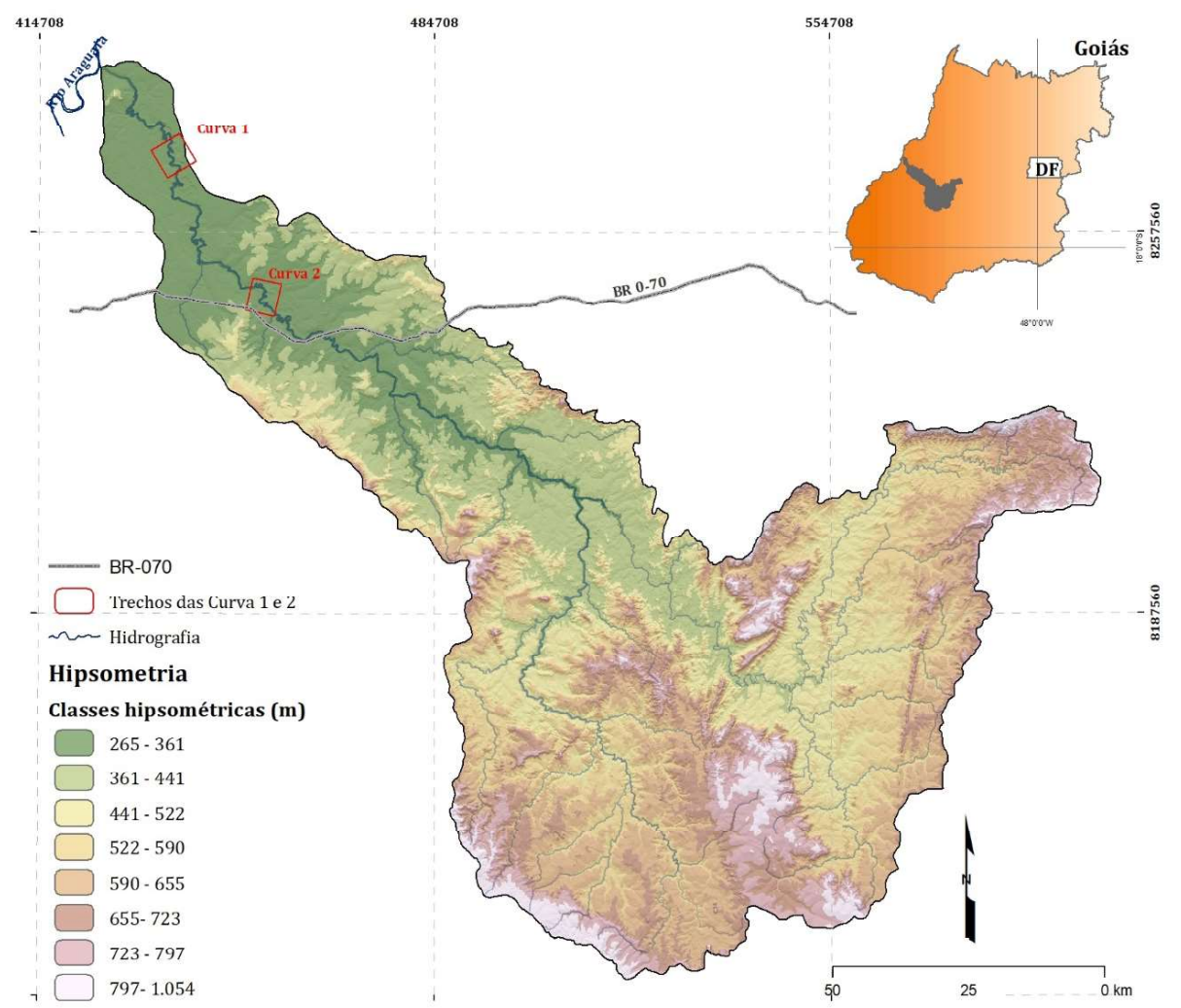

Figura 1 - Localização das Curvas 1 e 2 - Bacia Hidrográfica do Rio Claro

Quadro 1: Características Morfométricas da Bacia Hidrográfica do Rio Claro

\begin{tabular}{|l|c|}
\hline \multicolumn{2}{|c|}{ Características Morfométricas } \\
\hline Área de drenagem $\left(\mathrm{A}_{\mathrm{D}}\right)$ & $10.276 \mathrm{~km}^{2}$ \\
\hline Perímetro da bacia & $704 \mathrm{~km} ;$ \\
\hline Comprimento aproximado do curso d'água principal & $350 \mathrm{~km}$ \\
\hline Declividade média equivalente do talvegue $\left(\mathrm{S}_{\mathrm{i}}\right)$ & $0,35 \mathrm{~m} / \mathrm{km}$ \\
\hline Fator de forma $\left(\mathrm{K}_{\mathrm{F}}\right)$ & 0,08 \\
\hline
\end{tabular}


A precipitação média anual na bacia hidrográfica é $1560 \mathrm{~mm}$, ocorrendo um período chuvoso de outubro a março (Estação INMET - Código 1551001). De acordo com os dados da estação meteorológica de Montes Claros de Goiás (Código ANA -24950000), a maior cheia do rio Claro na estação chuvosa durante o período de amostragem de 2013-2014 atingiu a cota de $650 \mathrm{~cm}$. A estação está localizada no Rio Claro (latitude 431975 e longitude 8278275), cerca de $18 \mathrm{~km}$ a jusante da Curva
1, com área de drenagem de $10.100 \mathrm{~km}^{2}$. Ao longo do período de 2004 a 2014 (Figura 2) é observado que o nível do Rio Claro pode chegar a cota acima de $8 \mathrm{~m}$ e vazões muito próximas a $1000 \mathrm{~m}^{3} / \mathrm{s}$, enquanto que a cota média da cheia diária mensal do período chuvoso foi de $574 \mathrm{~cm}$. Isso significa que as taxas de erosão das margens das duas curvas amostradas neste estudo foram maiores quando comparado a eventos de vazões e cotas de cheias médias.

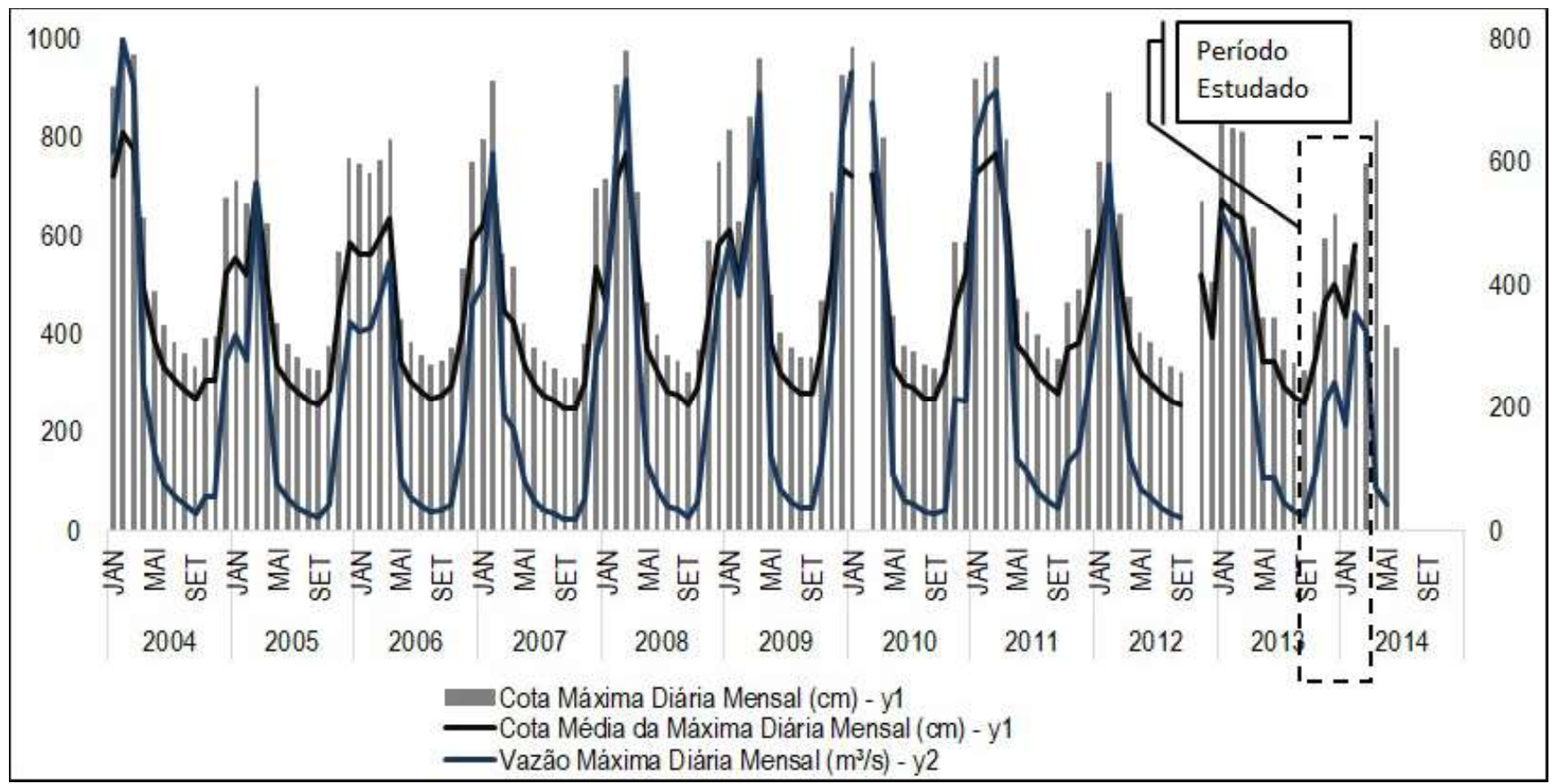

Figura 2 - Gráfico Cota-Vazão Rio Claro 2004-2014. Fonte: ANA e INMET (2018)

O baixo curso do rio Claro, onde localiza-se as duas curvas estudadas (Figura 1), apresenta uma extensa planíce aluvial alongada com características de deslocamento lateral recente do rio. Meandros abandonados ou lagos de meandros (oxbow lakes), barras de meandros (point bars), diques marginais, bacia de inundação, paleomeandros e terraços fluviais são formas de relevo abundantes na planície aluvial das duas curvas amostradas, indicando a migração lateral elevada dos meandros. Castro et al. (2014) demonstraram que essa migração lateral dos meandros constitui a dinâmica atual do baixo rio Claro, ao comparar a evolução dos meandros entre 1988 e 2012.

\section{Materiais e Métodos}

Dois critérios principais foram empregados para seleção das curvas dos meandros estudados. O primeiro refere-se à ocorrência de migração ativa do canal, constatada pelos processos de migração observados por imagens orbitais em Castro et al. (2014). O segundo critério se trata da margem côncava de ambas curvas apresentarem uma fração com vegetação ciliar preservada e outra fração sem vegetação ciliar, permitindo verificar a influência da vegetação sobre a erosão marginal. Na figura 3 são apresentadas as duas curvas selecionadas, onde observa-se a descontinuidade da presença de vegetação ciliar.

Conforme a figura 3 , na curva 1 foram demarcadas sete (7) seções verticais e na curva 2, $30 \mathrm{~km}$ a montante da curva 1, foram demarcadas cinco (5) seções. As seções verticais em ambas curvas foram utilizadas para determinar as taxas de erosão sobre as margens côncavas e as composições faciológicas e coletar amostras para ensaios laboratoriais quanto a textura granulométrica e desagregação espontânea sob condições saturadas. 


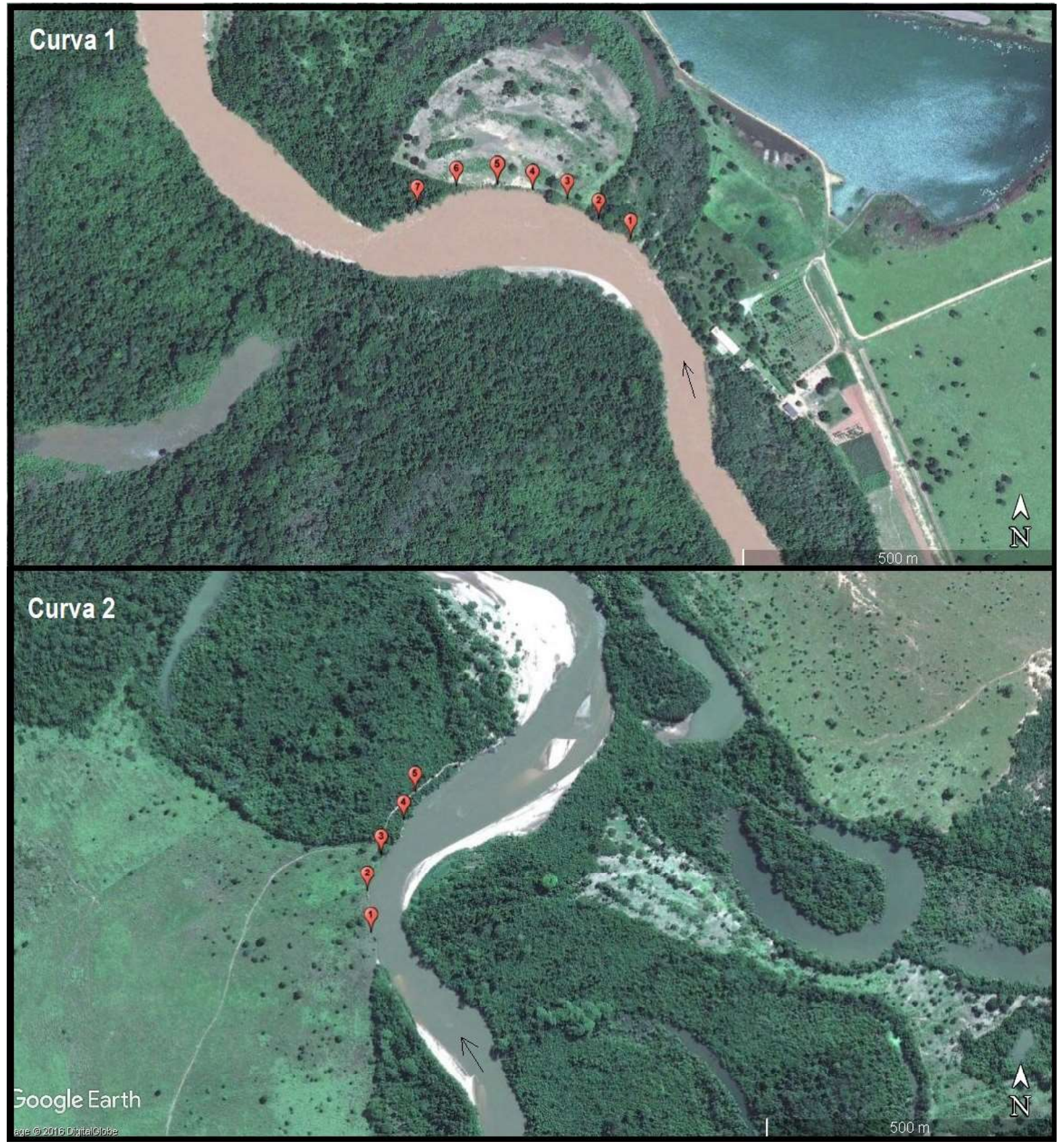

Figura 3 - Curva 1 (UTM22L 438151/8271442-281m) e Curva 2 (UTM22L 454071/8246354-289m) - Rio Claro, Goiás-GO. As setas no interior do canal indicam a direção do fluxo fluvial, enquanto que os pontos em vermelho indicam os locais onde as seções verticais de amostragem foram instaladas.

Buscou-se utilizar procedimento capaz de registrar o recuo da margem em função da erosão marginal (bank erosion), bem como demonstrar a resposta dos diferentes depósitos sedimentares e a influência que a presença e ausência da vegetação ciliar têm nas margens. Para tanto, observou os trabalhos realizados em clima Temperado que utilizaram pinos de erosão, (erosion pins) como Zaimes et al. (2005), Capello, (2008), Hooke (2008) e Coffman (2009). Ainda que as condições climáticas diferem do baixo curso do Rio Claro, este procedimento metodológico em sistemas fluviais tropicais também foram aplicados por Dias, (2012) e Souza e Cunha (2007).

Optou-se por utilizar os pinos de erosão (erosion pins) para a análise da erosão marginal durante a estação chuvosa de 2013-2014. Pinos de aço foram instalados nas margens côncavas das duas curvas do canal e perfi- 
lados em seções verticais equidistantes horizontalmente em $60 \mathrm{~m}$ (figuras 3 e 4). A fixação dos pinos ao longo das margens teve como critério a ampla distribuição nas curvas côncavas, de modo a abranger os diferentes materiais constituintes das margens e as frações das curvas com vegetação ciliar presente e ausente.

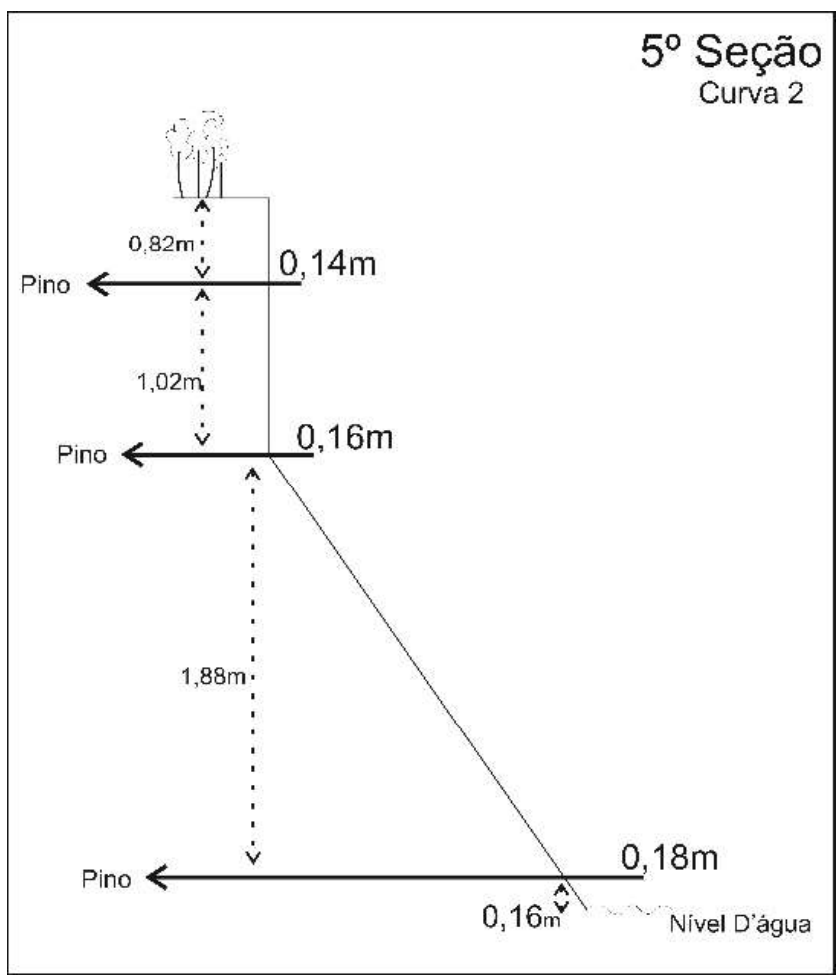

Figura 4 - Disposição dos pinos em seção vertical na margem côncava do canal. Exemplo Curva 2, Seção 5.

Em cada seção vertical, os pinos foram dispostos na margem em três posições: a inferior, correspondente ao nível da lamina d'água do período de vazante, a média altura e a superior, próximo ao topo da margem (Figura 4). No total foram instalados 21 pinos na curva 1, distribuídos em 7 seções; e, na curva 2 , foram usados um total de 15 pinos ao longo de 5 seções verticais. Houve um total de 4 seções retiradas por transeuntes, perfazendo 12 pinos sem registro de dados.

Para conhecer a taxa da erosão nas margens, foram feitas medições do comprimento da porção exposta de cada pino, logo após sua instalação, antes do período chuvoso em 2013-2014. Ao encerrar o período chuvoso de 2013-2014 foram feitas novas medições da porção exposta para comparar com a primeira medição, determinando a taxa de exumação do pino devido o recuo da margem, causado pela erosão no período, correspondente a diferença entre o registro inicial e final.

Os resultados obtidos da erosão foram apresentados de modo a observá-los ao longo das curvas. Para tanto, os dados foram interpolados pelo método do tipo Vizinho Natural (Equação 1), acoplados a um SIG (Sistema de Informação Geográfica), possibilitando espacializar as taxas encontradas ao longo das curvas e a relação entre o total de erosão, conforme:

$$
\mathrm{z}=\sum_{i=l}^{n} \mathcal{W}_{i} \mathrm{z}_{i}
$$

onde:

- $\boldsymbol{Z}$ representa o valor interpolado para o nó de um "Grid";

. $\boldsymbol{Z i}$ representa os valores das amostras vizinho ao nó; e, - Wi representa o peso obtido em função do tipo de método de interpolação.

De modo a verificar se as taxas de erosão marginal são comparáveis entre si, bem como estabelecer um comportamento hidráulico similar para as curvas selecionadas, foram analisados aspectos geométricos dos meandros. As variáveis geométricas levantadas foram o raio de curvatura $(R c)$ e a largura do canal $(w)$, a fim de 
determinar a razão $R c / w$ (Tabela 1). $\mathrm{O} R c$ (raio do círculo ajustado à curva do meandro) e a $w$ foram obtidos a partir de imagens de satélites, conforme Castro et al. (2014).

Segundo Christofoletti (1981) e Stevaux e Latrubesse (2017), a razão $R c / w$ permite a comparação entre meandros de diferentes tamanhos e representa um parâmetro geométrico importante por refletir o comportamento hidráulico do fluxo fluvial em canais meandrantes. Williams (1986) e Hickin e Nanson (1975; 1984) demonstraram que $R c$ oscila entre 2 e 3 vezes $w$ $(R c=2 w$ a $R c=3 w)$. Christofoletti (1981) encontrou o mesmo intervalo para rios do Sudeste do Brasil. As curvas do baixo Rio Claro, selecionadas neste estudo, apresentaram desempenho similar (Tabela 1). A razão $R c / w$ média foi 3 e 2,9 para a curva 1 e para o trecho meandrante da curva 2 , respectivamente.

Tabela 1: Geometria das curvas meândricas selecionadas. $R c$ e $w$ constituem as variáveis geométricas raio de curvatura $(R c)$ e largura média do canal $(w) ; R c / w$ é a razão entre o raio de curvatura e a largura do canal. A curva 1 é a curva meândrica selecionada mais a jusante no baixo Rio Claro, enquanto a curva 2 é a curva meândrica selecionada mais a montante (Figuras 1 e 3 ). As curvas $2 a, 2 b$ e 2 c constituem curvas a jusante no mesmo trecho meandrante da curva 2. Os anos 1965, 1998 e 2012 são os mesmo para o levantamento dos processos de migração lateral do baixo Rio Claro, determinados por Castro et al. (2014).

\begin{tabular}{|c|c|c|c|c|c|c|c|c|c|c|c|}
\hline & \multicolumn{3}{|c|}{$R c$} & \multicolumn{3}{|c|}{$w$} & \multicolumn{5}{|c|}{$R c / w$} \\
\hline & 1965 & 1998 & 2012 & 1965 & 1998 & 2012 & 1965 & 1998 & 2012 & \multicolumn{2}{|c|}{ média } \\
\hline Curva 1 & 216 & 232 & 283 & 70 & 79 & 79 & 3,5 & 2,9 & 3,0 & \multicolumn{2}{|c|}{3,0} \\
\hline Curva 2 & 100 & 93 & 167 & 65 & 56 & 92 & 1,5 & 1,6 & 1,8 & 1,66 & \multirow{4}{*}{2,9} \\
\hline Curva 2a & 188 & 130 & 165 & 42 & 60 & 52 & 4,4 & 2,1 & 3,1 & 3,1 & \\
\hline Curva 2b & - & - & 114 & - & - & 48 & - & - & 2,3 & 2,3 & \\
\hline Curva 2c & 220 & 255 & 207 & 66 & 58 & 42 & 3,3 & 4,3 & 4,9 & 4,3 & \\
\hline média & 181 & 177,5 & 187,2 & 60,7 & 63,2 & 62,6 & & & & & \\
\hline
\end{tabular}

Como os valores de $R c$ e $w$ variam entre sucessivos meandros, bem como ao longo do tempo devido a migração lateral (HICKIN; NANSON, 1984), foi determinado as variáveis $R c$ e $w$ e a razão $R c / w$ para os anos na mesma estação climática ( $w$ semelhantes devido sua proporcionalidade com a vazão), levantados por Castro et al. (2014). A razão $R c / w$ para a curva 2 mostrou valores menores (Tabela 1) pela presença de um terraço fluvial (depósitos aluviais mais resistentes) na margem esquerda. O terraço confinou a evolução do meandro da curva 2 (CASTRO et al., 2014), limitando o crescimento do $R c$ até o intervalo $R c=2 w$ a $R c=3 w$, conforme indicado por Hickin e Nanson (1984). Desse modo, foi determinado a razão $R c / w$ para um trecho imediatamente a jusante da curva 2 ( $2 \mathrm{a}, 2 \mathrm{~b}$ e $2 \mathrm{c}$, Tabela 1). Isso não foi possível para a curva $2 b$ para os anos de 1965 e 1998, uma vez que a evolução acelerada dos meandros naquele trecho não desenvolveu nenhuma curva, como visto também por Castro et al. (2014). Apesar disso, o intervalo da razão $R c / w$ para o trecho da curva 2 (curvas 2, 2a, 2b e 2c) alcançou valor médio de 2,9.
O desempenho da razão $R c / w$ (Tabela 1) demonstra a similaridade entre as curvas selecionadas para este estudo, principalmente quanto ao comportamento hidráulico responsável pelas taxas de erosão marginal (migração lateral). Os fundamentos para isso são: (i) ao intervalo da razão $R c / w$ oscilar entre $R c=2 w$ e $R c$ $=3 w$; (ii) às curvas selecionadas funcionarem como sistemas abertos em planícies aluviais, e; (iii) às planícies nas quais as curvas selecionadas se desenvolvem apresentam a mesma natureza, grandeza e interação das variáveis e fatores do sistema fluvial do baixo Rio Claro.

Os materiais constituintes das margens côncavas de ambas as curvas foram classificados em termos faciológicos, adaptando a proposta de Miall (1996), considerando estrutura, disposição, granulometria e espessura dos pacotes de depósitos para cada seção vertical. O quadro 2 apresenta as características utilizadas para a classificação faciológica das margens. 
Quadro 2: Características faciológicas dos materiais constituintes das margens das curvas 1 e 2.

\begin{tabular}{|c|c|c|}
\hline Código & Granulometria e estrutura & Características observadas na área: \\
\hline $\mathrm{Gm}$ & $\begin{array}{l}\text { Seixos maiores que } 2 \mathrm{~cm} \text {, bem } \\
\text { arredondados. Estrutura maciça. }\end{array}$ & $\begin{array}{l}\text { Nas porções basais apresentam imbricados, com } \\
\text { contato plano-paralelo e granulodecrescência } \\
\text { ascendente. }\end{array}$ \\
\hline Gms & $\begin{array}{l}\text { Seixos arredondados menores } \\
\text { que } 2 \mathrm{~cm} \text { e areia muito grossa } \\
\text { subordinariamente. Estrutura } \\
\text { maciça. }\end{array}$ & $\begin{array}{l}\text { Granulodecrescência ascendente; conformação plana a } \\
\text { difusa. Pacotes pouco espessos e continuidade lateral } \\
\text { restringe-se a poucos metros. }\end{array}$ \\
\hline $\mathrm{Sp}$ & $\begin{array}{l}\text { Areia grossa a mal selecionada. } \\
\text { Estrutura cruzada plana. }\end{array}$ & $\begin{array}{l}\text { Contato abrupto entre as camadas. } \\
\text { Granulodecrescência ascendente interna. Espessura } \\
\text { variável de até } 2 \mathrm{~m} \text {, com continuidade lateral variável, } \\
\text { podendo ultrapassar dezenas de metros. }\end{array}$ \\
\hline St & $\begin{array}{l}\text { Areias média e fina. Estrutura } \\
\text { cruzada acanalada. }\end{array}$ & $\begin{array}{l}\text { Quando rasos, a estrutura encontra-se alterada por } \\
\text { pedogênese. Possuem espessuras de } 1 \text { a } 2 \mathrm{~m} \text { e ampla } \\
\text { continuidade lateral. }\end{array}$ \\
\hline $\mathrm{Sh}$ & $\begin{array}{l}\text { Areia fina. Estrutura plana- } \\
\text { horizontal. }\end{array}$ & $\begin{array}{l}\text { Espessura de até } 1 \mathrm{~m} \text {, com continuidade lateral restrita } \\
\text { a poucos metros. São corpos comuns na margem da } \\
\text { curva } 2 .\end{array}$ \\
\hline $\mathrm{F} 1$ & $\begin{array}{l}\text { Silte grosso. Estrutura laminar } \\
\text { ondulada. }\end{array}$ & $\begin{array}{l}\text { São corpos superficiais com presença mais frequente } \\
\text { na curva } 2 \text {. Ampla continuidade lateral de espessuras } \\
\text { de até } 0,5 \mathrm{~m} \text {. }\end{array}$ \\
\hline Fm & $\begin{array}{l}\text { Pelitos com presença ampla de } \\
\text { matéria orgânica }(\mathrm{MO}) \text {. Estrutura } \\
\text { maciça. }\end{array}$ & $\begin{array}{l}\text { São corpos superficiais com espessura de até } 0,5 \mathrm{~m} \text { e } \\
\text { continuidade lateral restrita. }\end{array}$ \\
\hline
\end{tabular}

Foram coletadas amostras deformadas e indeformadas em cada seção para análises laboratoriais. As amostras deformadas foram levadas ao Laboratório de Geomorfologia, Pedologia e Geografia Física (LABOGEF-UFG) para análise granulométrica. As amostras foram preparadas em solução com dispersante químico e agitador mecânico e processadas no Granulômetro a Laser (Mastersizer 2000E ${ }^{\circledR}$ ), configurado para a escala de Wentworth (1922).

As amostradas indeformadas foram submetidas ao ensaio de desagregação em submersão aquosa, baseado nos experimentos de Holmgren e Flanaga (1977) e adaptado por Santos (1997) para identificação da desagregação e caracterização geotécnica de materiais. As amostras foram colhidas em caixas de 14 $\mathrm{cm}^{3}$ obtendo-se material indeformado de onde foram fixados os pinos. Alguns setores das margens não foram amostrados para este experimento, pois os depósitos eram totalmente incoesos, impossibilitando a coleta de amostras indeformadas.

O ensaio em submersão consistiu em colocar as amostras indeformadas sobre uma superfície porosa, ao qual possibilitou a ascensão da água desde a sua base. $\mathrm{O}$ nível d'água foi mantido na base das amostras durante 15 minutos. Em seguida, o nível d'água foi elevado em $1 / 3$, depois $2 / 3 \mathrm{em}$ intervalos iguais de 15 minutos, até a submersão completa das amostras, a qual foi mantida por 24 horas. Após cada etapa da elevação do nível da água, bem como após 24 horas de submersão completa, registrou-se o comportamento das amostras em 4 tipos de desagregação, segundo Holmgren e Flanagan (1977), conforme o quadro 3 . 
Quadro 3: Tipologia de desagregação de amostras sob ensaio de submersão aquosa, baseado em Holmgren e Flanaga (1977) e adaptado por Santos (1997).

\begin{tabular}{|c|c|l|}
\hline $\begin{array}{c}\text { Tipo de } \\
\text { desagregação }\end{array}$ & Código & Característica \\
\hline Sem Resposta & SR & Quando a amostra mantém a sua forma e tamanho originais \\
\hline Fraturamento & Fr & $\begin{array}{l}\text { Quando a amostra se deforma em fragmentos, mantendo as faces } \\
\text { externas da configuração original. Segundo Santos (1997), o principal } \\
\text { mecanismo atribuído ao processo é a expansão osmótica. A água tende } \\
\text { a mover-se para dentro a fim de reduzir a concentração, causando } \\
\text { expansão }\end{array}$ \\
\hline Dispersão & Ds & $\begin{array}{l}\text { As paredes tornam-se difusas ao formar uma "nuvem" coloidal que } \\
\text { cresce à medida que a amostra é dissolvida, do qual associam as maiores } \\
\text { pressões de expansão, suficientes para provocar a separação entre } \\
\text { partículas individuais }\end{array}$ \\
\hline Abatimento & Ab & $\begin{array}{l}\text { Quando a amostra se desintegra formando uma pilha de material } \\
\text { desestruturado. Os mecanismos primários causam a desintegração, } \\
\text { como por exemplo, hidratação e desaeração que atuam gerando pressões } \\
\text { positivas que desagregam a amostra }\end{array}$ \\
\hline
\end{tabular}

O comportamento da amostra durante o ensaio de desagregação representa a estabilidade geotécnica do material. Quando a amostra não responde a submersão $($ sem resposta $=\mathrm{SR})$, após 24 horas em submersão completa, significa o maior grau de estabilidade geotécnica, ou seja, o material constituinte da margem apresentaria maior resistência a ação erosiva do fluxo fluvial. No outro extremo, quando a amostra sofre abatimento $(\mathrm{Ab})$ nos primeiros 15 minutos do ensaio, com a água em contato apenas na base da amostra, significa o menor grau de estabilidade, isto é, o material constituinte da margem apresentaria menor resistência a ação erosiva do fluxo fluvial. Os comportamentos intermediários das amostras durante o ensaio representam graus intermediários de estabilidade.

\section{Resultados e Discussão}

\subsection{Curva 1}

Os materiais constituintes da margem côncava da curva meândrica 1 apresentaram características de depósitos sedimentares formados em ambiente fluvial. Desse modo, não foram observadas severas distinções na late- ralidade dos materiais constituintes da margem. Porém, a margem apresentou granulodecrescência ascendente em toda a seção; característica comum na sucessão de depósitos de rios meandrantes (NANSON, 1980; KNIGHTON, 1984; STEVAUX e LATRUBESSE, 2017).

Ao todo foram descritos 7 perfis colunares ao longo da margem direita (côncava) da curva 1 (Figura 5). Classificou-se a granulometria, estrutura e as caraterísticas locais dos depósitos, associando a 7 códigos faciológicos (Quadro 2), de modo a verificar as variações nos materiais constituintes que possam influenciar as taxas de erosão marginal e migração lateral.

Os perfis 1, 2 e 7 estão sob mata ciliar preservada, enquanto que os perfis de 3 a 6 ocorrem sob pastagem. Em relação aos materiais constituintes, os perfis apresentaram uma variedade faciológica predominantemente arenosa. Em todos os perfis, notou-se a granulodecrescência ascendente, exceto nos perfis 1 e 2 , onde ocorrem as fácies mais grosseiras em profundidades intermediárias do perfil. As camadas em cada perfil apresentaram espessuras similares, principalmente entre aqueles próximos entre si, porém os pacotes pelíticos mais espessos aparecem nos perfis 4,5 e 6 . 


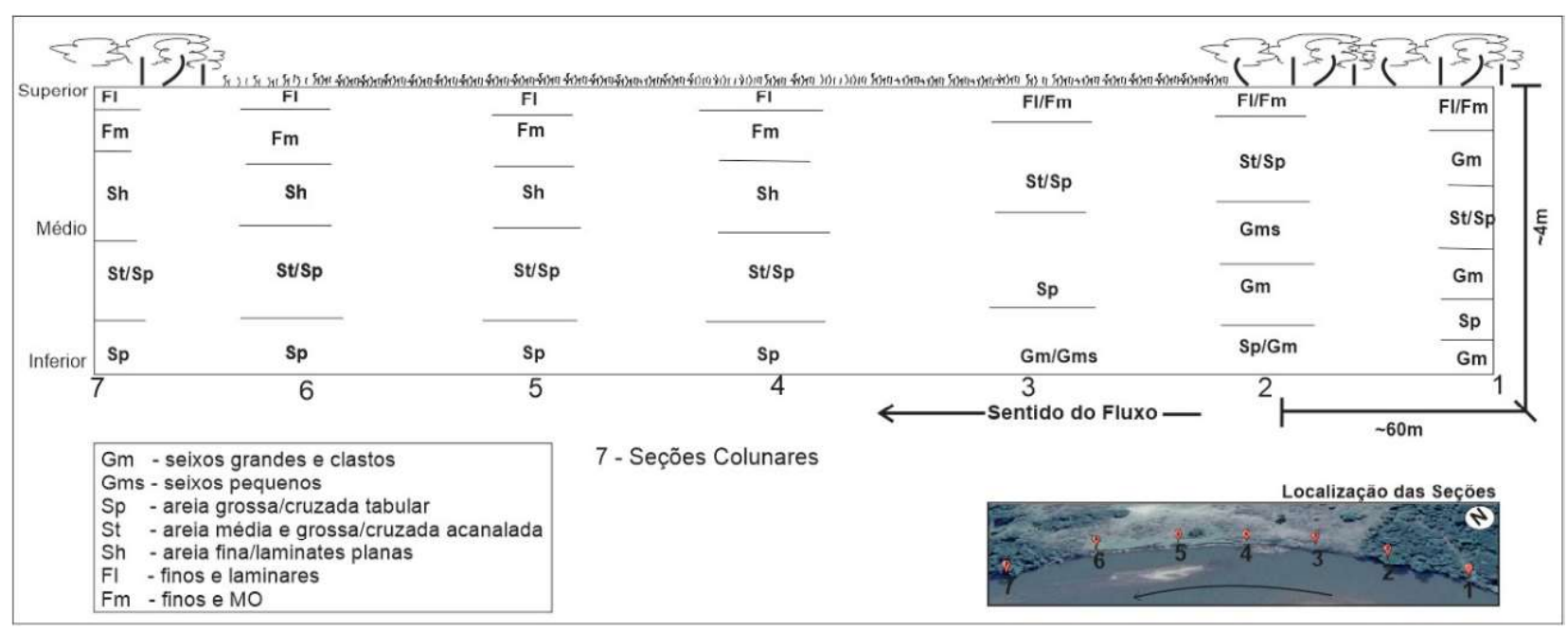

Figura 5 - Disposição faciológica ao longo da margem da Curva 1, conforme Quadro 2.

As taxas de erosão marginal na curva 1 (Figura 6) foram agrupadas em classes de valores, na qual $0-16 \mathrm{~cm}$ corresponde a classe dos valores menores de exumação dos pinos de monitoramento (taxa de erosão marginal); e entre $120-130 \mathrm{~cm}$, os valores maiores. Os pinos locados nas seções 1,5 e 6 foram retirados por transeuntes e impossibilitou a avaliação da erosão nestas seções. Nos demais, como os valores absolutos das taxas entre os pinos tiveram grande variação, algumas taxas de menor erosão ficaram imperceptíveis na Figura 6. O perfil 7 serve de exemplo, uma vez que os pinos superior e inferior apresentaram taxas de 0,4 e $0,9 \mathrm{~cm}$, respectivamente; enquanto que a taxa do pino intermediário alcançou a classe $120-130 \mathrm{~cm}$.
A variação das taxas de erosão marginal (Figura 6) na curva 1 ocorreu lateralmente ao longo de toda a margem, bem como entre os pinos de um mesmo perfil colunar (variação vertical). As maiores taxas de erosão ocorreram entre os perfis 2 e 4 , variando entre $64-80 \mathrm{~cm}$ e 120-130 cm, principalmente na porção inferior desses perfis. Acredita-se que isso ocorreu, em parte, por corresponder a seção de entrada da curva (metade montante da margem côncava da curva), a qual as águas do canal impactam diretamente, incidindo as maiores velocidades e turbulência da corrente. A menor variação horizontal (cerca de $58 \mathrm{~cm}$ ) em relação aos demais pinos da porção inferior demonstra a concentração do impacto hidráulico e solapamento pelo fluxo d'água nesta seção da margem.

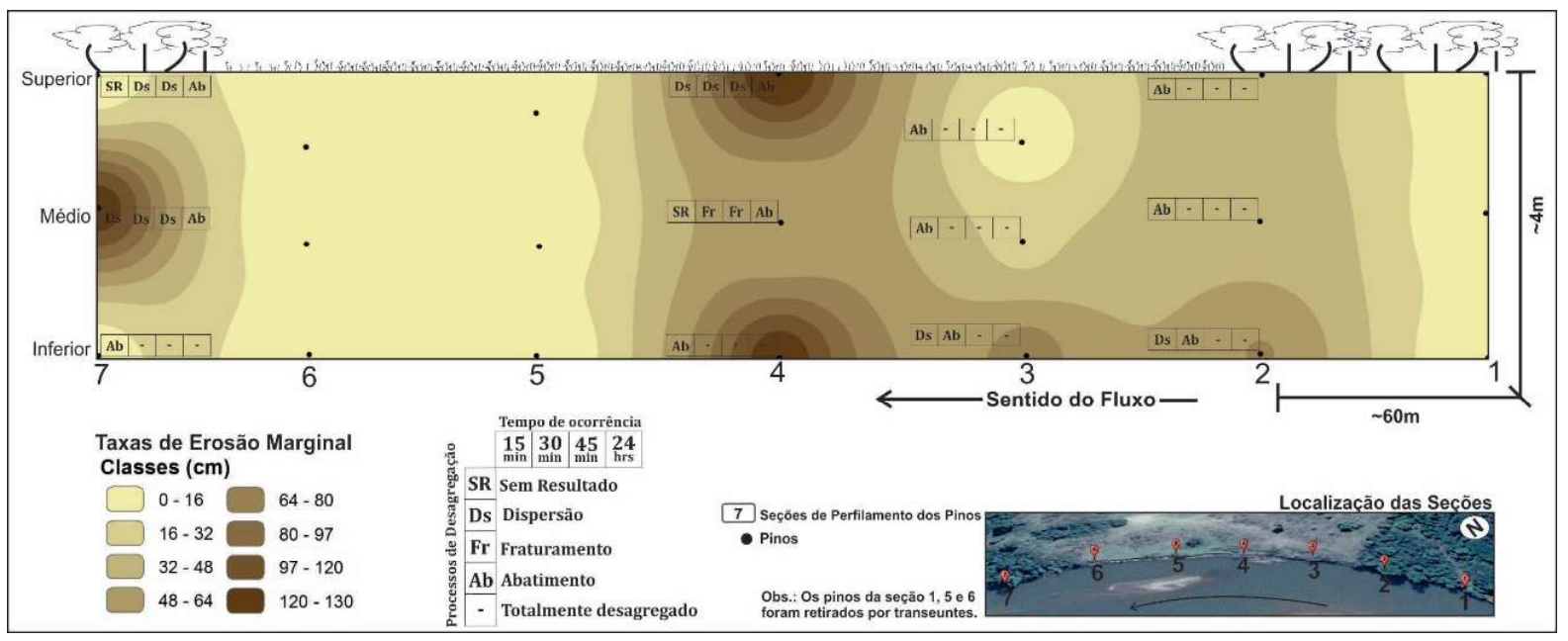

Figura 6 - Distribuição da erosão ao longo da margem da Curva 1 associado a desagregação de materiais segundo o tempo de ocorrência do processo, conforme Quadro 3. 


\section{A Influência dos Materiais das Margens e da Vegetação Ciliar na Erosão de Meandros: O Caso do Rio Claro}

As taxas de erosão marginal na porção superior da curva 1 apresentou-se heterogênea, variando horizontalmente entre 0 e $130 \mathrm{~cm}$. Essa distribuição das taxas na porção superior pode estar relacionada à cobertura vegetal. Sob mata ciliar preservada, a porção superior dos perfis 2 e 7 apresentaram taxas de erosão de 4 e $40 \mathrm{~cm}$, respectivamente, mesmo tendo sofrido taxas elevadas nas porções inferiores. Com a ausência da vegetação ciliar, aliada ao impacto hidráulico da seção central da curva, a porção superior do perfil 4 alcançou valor acima de $120 \mathrm{~cm}$ de exumação.

Essas variações também foram constatadas por outros estudos. Comparado aos resultados obtidos aqui no Rio Claro, Dias (2012) observou valores bem menores para o Rio Guabiroba no Paraná, encontrando taxas médias de erosão marginal entre 4,13 e 4,45 cm em dois períodos chuvosos (2010-2012). A erosão máxima identificada por Dias (2012) chegou a $45 \mathrm{~cm}$, do qual associou às descargas máximas do período estudado. Hooke (1980), monitorando por 2 anos os pinos instalados nas margens do Rio Devon (Inglaterra), observou taxas erosivas entre 8 e $118 \mathrm{~cm} /$ ano, semelhante aos observados aqui na curva 1 do Rio Claro.

Por outro lado, os resultados da desagregação espontânea sob condições saturadas de amostras dos materiais da margem da curva 1 ajudam a esclarecer as taxas de erosão marginal. Todas as amostras dos perfis 2 e 3 sofreram desagregação por abatimento nos primeiros instantes após a imersão parcial, certamente por se tratar de fáceis arenosas inconsolidadas. As amostras inferiores dos perfis 2 e 3 sofreram dispersão nos primeiros 15 minutos de submersão parcial, seguindo por abatimento após 30 minutos. As amostras médio-superiores dos perfis 4 e 7 somente sofreram dispersão ou fraturamento nos 30 minutos iniciais em submersão parcial, alcançando abatimento após 24 horas de submersão total. Contudo, as amostras inferiores dos perfis 4 e 7 sofreram abatimento em poucos minutos de submersão parcial.

Acredita-se que esses resultados de desagregação da curva 1 estão relacionados a granulometria das amostras. As amostras que sofreram abatimento na fase inicial dos ensaios compõem-se de materiais mais grosseiros ( $\geq$ areias médias), como as amostras dos perfis 2 e 3 e inferiores dos perfis 4 e 7 , enquanto que amostras que sofreram abatimento somente após 24 horas submersas, constituem-se de materiais mais finos (areia fina a argilas).

Observou-se uma convergência entre os resultados do ensaio de desagregação, a granulometria e as taxas de erosão da porção inferior da curva 1 . A porção inferior desta curva, dominada por sedimentos grosseiros, como areias médias e seixos, tiveram as maiores taxas de erosão (Figura 7) com as amostras desagregando rapidamente nos primeiros 15 a 30 minutos submersas (Figura 6). Neste caso, a porção inferior teria sofrido mais erosão, pois estes sedimentos arenosos permanecem em condição saturada com frequência maior durante o ano, pois encontram-se mais próximo do nível de águas médias e baixas. Por desagregam-se mais facilmente quando submersos, são removidos pela ação mecânica do fluxo fluvial.

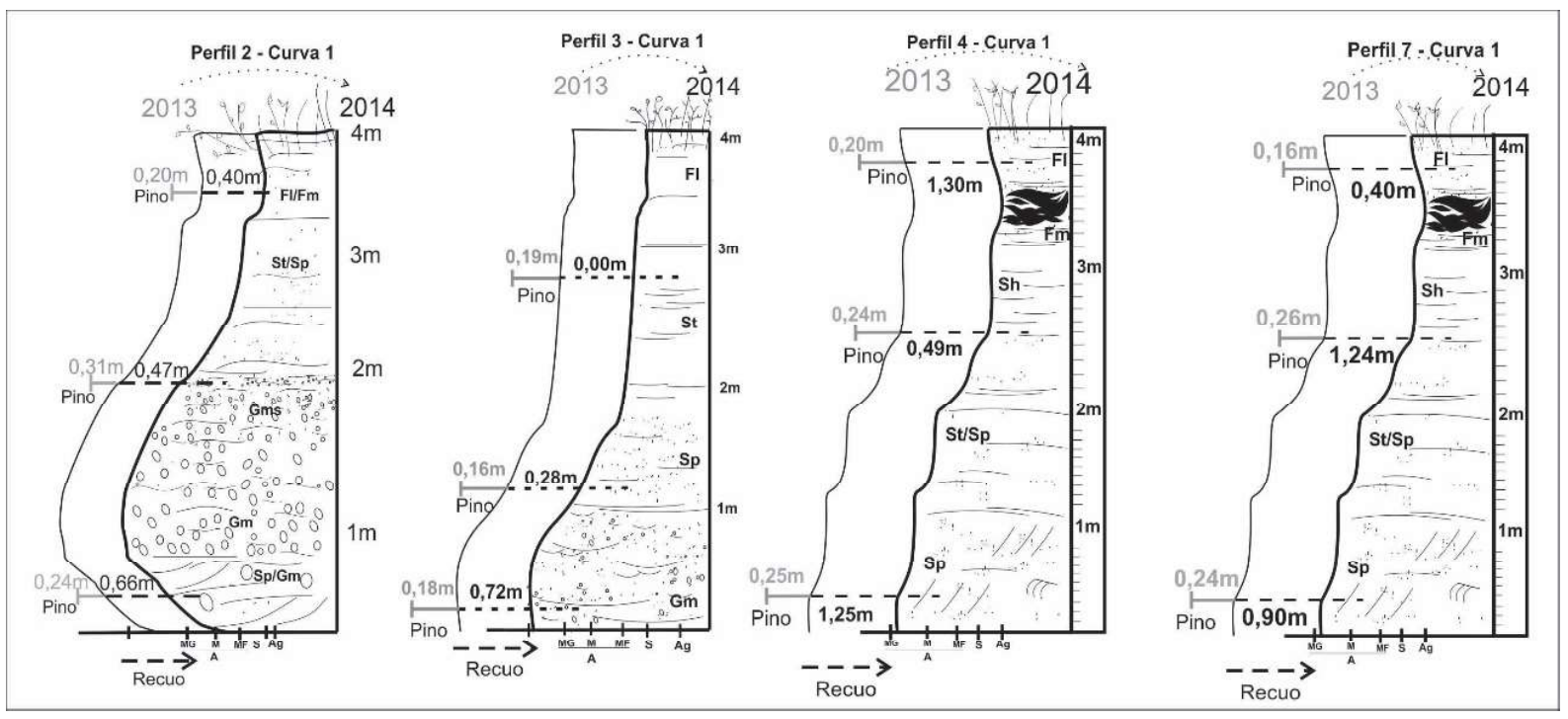

Figura 7 - Perfis faciológicos da Curva 1 e taxas de erosão entre 2013 e 2014. 
Essa convergência entre os resultados também pode ser percebida nas porções médio-superiores dos perfis 2 e 3 . Também dominada por sedimentos grosseiros, mostraram-se mais suscetíveis a desagregação, apresentando taxas moderadas de erosão marginal. Por outro lado, a porção médio-superior do perfil 4, embora menos suscetível a desagregação (abatimento após 24h), sofreram taxas elevadas de erosão devido ao impacto hidráulico na inflexão da curva 1 .

\subsection{Curva 2}

A curva 2 apresenta material constituinte granulometricamente semelhante ao da curva 1 , porém a variabilidade lateral é marcadamente distinta entre ambas curvas. A curva 2 também apresenta características de depósitos sedimentares formados em ambientes fluviais, com baixas distinções na lateralidade dos depósitos e granulodecrescência ascendente em toda a seção. Ao todo foram descritos 5 perfis colunares (Figura 8) e 6 códigos faciológicos associados aos materiais que constituem a margem (Quadro 2).

Os perfis de 1 a 3 encontram-se sob pastagem num nível topográfico mais elevado de um terraço, enquanto que os perfis 4 e 5 estão sob mata ciliar preservada no nível topográfico mais baixo da planície de inundação. As fácies da porção superior de toda a seção da curva apresentaram os materiais mais finos e maior teor de matéria orgânica. Nos perfis de 1 a 3 (terraço), ocorreram granulodecrescência ascendente, tendo em profundidade intermediária espesso pacote arenoso. Nos perfis 4 e 5 (planície), as camadas são menos espessas, com granulodecrescência ascendente típica apenas no perfil 4, pois no perfil 5 ocorre fácies arenosas (Sh) a 0,5 $\mathrm{m}$ do topo entre duas fácies pelíticas (Fl, Fm) (Figura 8).

As taxas de erosão marginal na curva 2 também apresentaram grande variação lateral, bem como entre os cinco perfis colunares descritos (variação vertical). Porém, as taxas apresentaram valores menores quando comparadas com a curva 1, visto que o intervalo 58,62 $-67 \mathrm{~cm}$ (Figura 9) representa a classe das maiores taxas de erosão dos pinos de monitoramento para a margem da curva 2, enquanto que para a curva 1 alcançaram $130 \mathrm{~cm}$. Essa diferença entre as duas curvas segue os valores observados em outros estudos e aos processos de migração lateral. Souza e Cunha (2007) ao estudarem o Rio Paraguai, observaram uma taxa de erosão marginal máxima de $25 \mathrm{~cm}$ no período chuvoso de 2001-2002, a partir do monitoramento de pinos instalados em 12 perfis. As taxas elevadas de erosão ocorridas para os trechos estudados do Rio Claro demonstram correlação entre erosão marginal e o padrão meandrante, visto que Castro et al. (2014) mostraram a acentuada migração lateral dos meandros dos mesmos trechos do Rio Claro no período de 1998 a 2012.

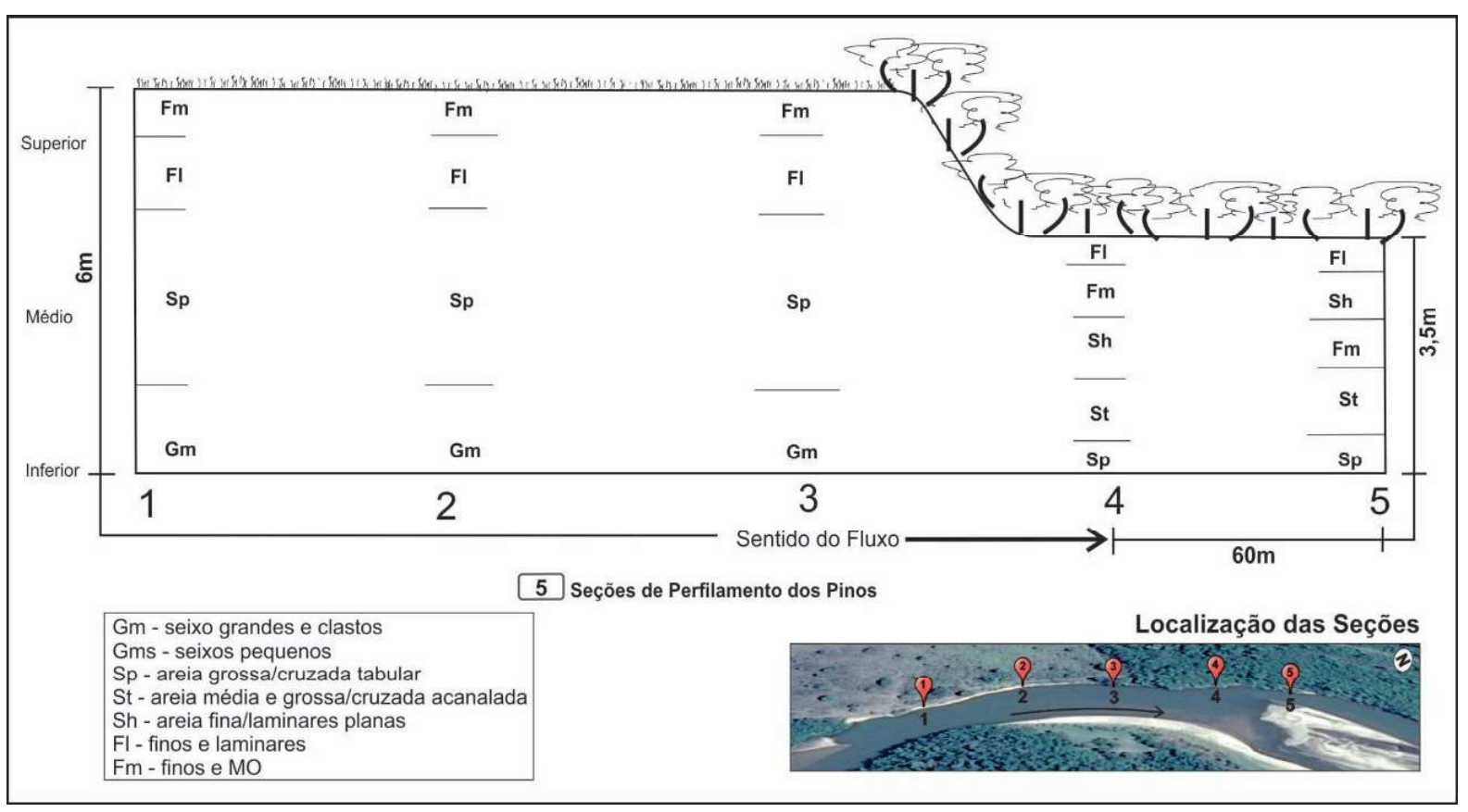

Figura 8 - Disposição faciológica ao longo da margem da Curva 2, conforme Quadro 2 


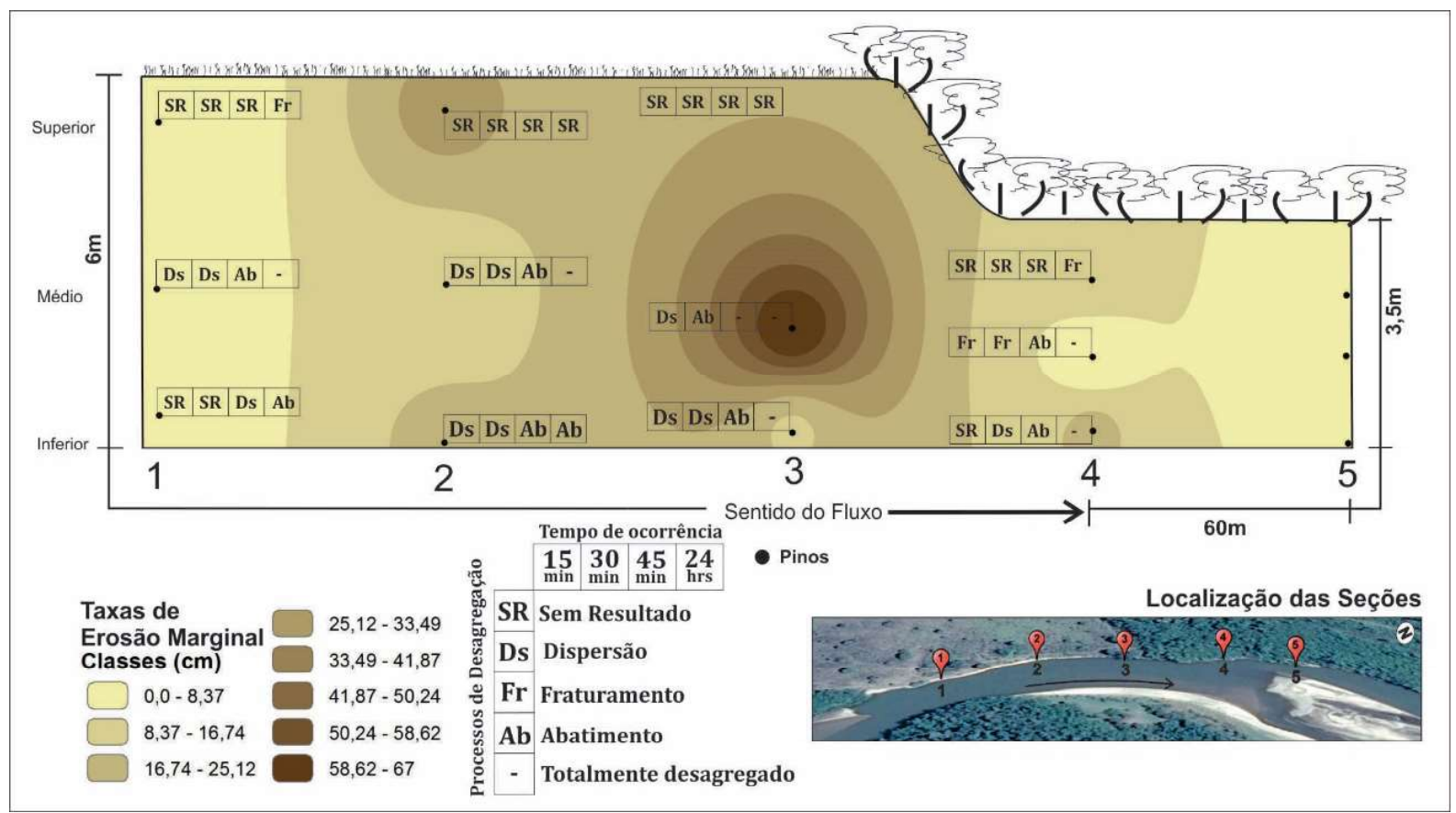

Figura 9 - Distribuição da erosão ao longo da margem da Curva 2 associado a desagregação de materiais segundo o tempo de ocorrência do processo, conforme Quadro 3

A porção superior dos perfis 2 e 3 (nível de terraço sob pastagem) registrou taxas de erosão maiores que do perfil 4 (nível de planície sob mata ciliar preservada). Enquanto a erosão exumou $29 \mathrm{~cm}$ do pino superior no perfil 2, as taxas não ultrapassaram $16 \mathrm{~cm}$ na porção superior do perfil 4 (Figura 9).

A distribuição dos valores das taxas de erosão ao longo da margem esquerda (côncava) da curva 2 mostra um desempenho similar entre as porções superiores e inferiores dos perfis estudados. Ao que parece os materiais mais grosseiros ( $\mathrm{Gm}$ - seixos grandes) na porção inferior da margem da curva 2 resistem mais a ação da erosão marginal, apesar de passarem mais tempo submerso ao longo do ano e por manterem-se próximos ao nível da água. Se comparado à porção inferior da curva 1 , ligeiramente mais arenosa, as taxas de erosão variaram acima de $32 \mathrm{~cm}$ (Figura 6), enquanto que na porção inferior da curva 2 não ultrapassaram $25 \mathrm{~cm}$ nos perfis 2 e 4 (Figura 9).

Em relação aos resultados do ensaio de desagregação espontânea sob condições saturadas, as amostras superiores dos perfis 2 e 3 não sofreram reação (SR), mantendo sua forma e tamanho originais mesmo frente a submersão total durante 24 horas. A porção superior do perfil 1 apresentou o mesmo desempenho, apenas fraturando após 24 horas. Comparativamente, amostras avaliadas por Santos (1997) que desempenharam este mesmo comportamento em submersão, foram subme- tidas ao ensaio de Inderbitzen, o qual indicou baixa erodibilidade.

As maiores taxas de erosão marginal na curva 2 ocorreram na porção intermediária do perfil 3. Novamente a combinação entre as fácies arenosas $(\mathrm{Sp})$ e as propriedades hidráulicas da corrente fluvial no centro da curva (impacto hidráulico direto do fluxo, posição das maiores velocidades e turbulência) demonstra exercer maior influência. Bartley et al. (2006) constataram situação similar ao detectarem erosão lateral em 8 sítios do Rio Daintree, entre 2004 e 2005, cujas taxas alcançaram $24 \mathrm{~cm}$, concentradas na porção central das curvas. Eles explicaram essas concentrações da erosão em virtude da maior quantidade de material arenoso naquele ponto da margem e a concentração das correntes fluviais de alta energia.

Além das características hidráulicas do fluxo, a natureza do material constituinte das margens sugere ser variável importante dos processos erosivos marginais de cursos d'água. Os resultados da desagregação espontânea sob condições saturadas de amostras dos materiais constituintes da margem da curva 2 ajudam a esclarecer as taxas de erosão marginal (Figura 9 e Figura 10). As amostras da porção média do perfil 3 sofreram a maior taxa de erosão na curva $2(67 \mathrm{~cm})$ e apresentaram a reação mais rápida no ensaio laboratorial, sofrendo desagregação espontânea por abatimento em 30 minutos 
de submersão. As amostras da porção média do perfil 2 e inferior do perfil 3, também formadas por areias grossas, abateram-se pouco mais tarde (aos $45 \mathrm{~min}$ ), porém sofreram taxas ligeiramente menores de erosão quanto mais afastadas do centro da curva 2.

As amostras médio-inferiores do perfil 4 também apresentaram esse desempenho. Formadas por areias, sofreram abatimento aos 45 minutos e taxas menores de erosão ocorreram quanto mais afastado do centro da curva. Por outro lado, as amostras superiores do perfil 4, compostas por finos, não reagiram ao ensaio de desagregação, apenas fraturando após 24 horas em submersão total.

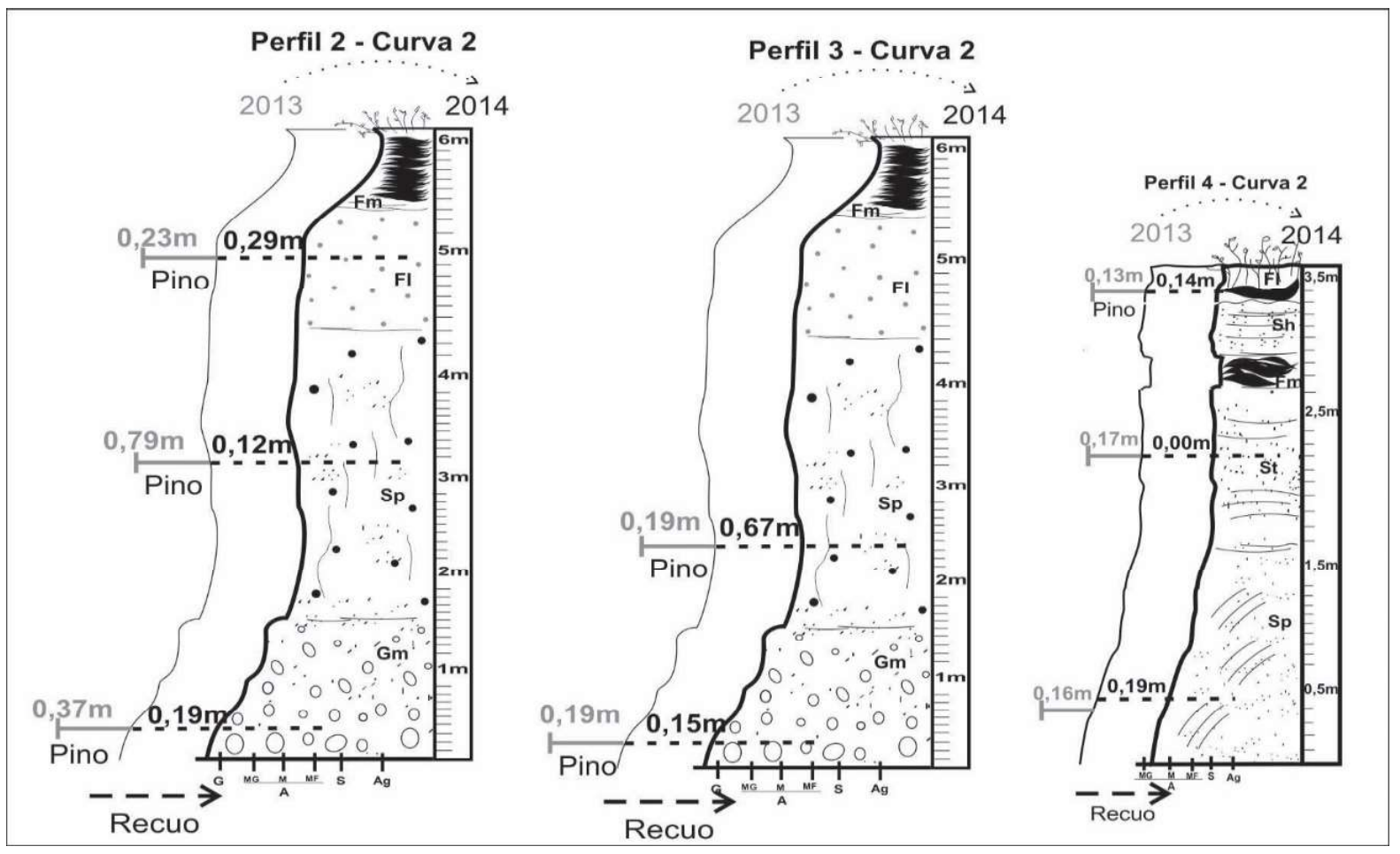

Figura 10 - Perfis faciológicos da Curva 2 e taxas de erosão entre 2013 e 2014.

\subsection{Comparação entre as curvas}

As taxas de erosão (exumação dos pinos de monitoramento) em ambas as curvas estudadas do Rio Claro se concentraram na porção central, junto ao eixo das curvas meândricas. Isso assinala a importância do fluxo da corrente fluvial na erosão marginal e migração lateral, em função do impacto hidráulico, das maiores velocidades e fluxo turbulento nos meandros (NANSON, 1980; KNIGHTON, 1984; CORNEY; et al., 2006; STEVAUX e LATRUBESSE, 2017).

As taxas de erosão da curva 1 foram maiores que as da curva 2. As maiores taxas da curva $1(130 \mathrm{~cm})$ foram cerca do dobro da curva $2(67 \mathrm{~cm})$, justamente junto ao eixo de inflexão das curvas meândricas. Cabe notar que, em ambas as curvas, as porções dominadas por areia médias e grossas sofreram as maiores taxas de erosão, enquanto que a maioria das porções com sedimentos mais finos apresentaram as menores taxas. Isso assinala a importância relativa da natureza dos materiais constituintes das margens na erosão marginal e migração lateral dos meandros, convergindo com as observações de Hickin e Nanson (1975), Constantine et al. (2009) e Souza e Cunha (2007).

Ao mesmo tempo, os resultados dos ensaios de desagregação espontânea sob condições saturadas mostraram que as amostras da curva 1 desagregaram-se mais rapidamente que as amostras da curva 2. Enquanto que a maioria das amostras da curva 1 sofreram abatimento entre 15 e 30 minutos do ensaio, as amostras da curva 2 abateram-se apenas após 45 minutos, tendo algumas amostras permanecido inalteradas ou apenas se fraturaram após 24 horas de submersão total durante o ensaio.

Deve ser lembrado que aproximadamente $65 \%$ da margem da curva 2 constitui um terraço, topogra- 
ficamente 2 metros acima do restante da curva 2, bem como de toda curva 1 . A presença desse nível de terraço, juntamente com a reação mais lenta a desagregação das amostras da curva 2, sugere certo desenvolvimento pedogenético, maior agregação e resistência a erosão marginal dos materiais constituintes. Por outro lado, a curva 1 encontra-se em nível topográfico mais baixo, que associado a variedade granulométrica de seixos até areias medias e finas, bem como a granulodecrescência ascendente e distribuição faciológica, sugere tratarem-se de depósitos inconsolidados de canal fluvial mais jovens, menos resistentes a desagregação por saturação e a ação mecânica da corrente fluvial. A fotointerpretação das imagens de satélite (Figura 3) permite notar a presença de cordões convexos (point bars), paleomeandros e meandros abandonados (oxbow lakes) na curva 1 e no nível baixo da planície de inundação da curva 2. Estas formas estão ausentes no nível de terraço da curva 2. Isto contribui para indicar que os depósitos da margem da curva 1 e do nível mais baixo (planície de inundação) da curva 2 são mais recentes que do nível de terraço da curva 2, que apresenta maior desenvolvimento pedogenético e estabilização dos materiais da margem do terraço da curva 2 .

Os resultados não foram suficientes para demonstrar o papel da vegetação ciliar em relação a erosão marginal, como demonstraram Micheli et al. (2004), por exemplo. Isso sugere o papel secundário da vegetação ciliar em contribuir para contenção da erosão marginal e migração lateral das curvas meândricas para rios de ordens hierárquicas equivalentes e superiores ao do Rio Claro ou sob condições de climas tropicais continentais do Centro-Oeste do Brasil, onde a vazão máxima dos rios não excede dez vezes as vazões médias (LATRUBESSE et al., 2005), diferente das condições de clima temperado de Micheli et al.(2004) e de outros estudos mencionados por eles. Estudos que indicam o tombamento de árvores em curvas meândricas e a presença de troncos como carga detrítica transportada por rios meandrantes (FERNANDEZ, 2004; BINDA e FERNANDEZ, 2011; MONTGOMERY; PIÉGAY, 2003; JEFFRIES et al. 2003) vão ao encontro do que sugere os resultados deste artigo. A vegetação ciliar tem papel mais importante na cadeia trófica da biota lótica e propriedades físico-químicas das águas, bem como pode contribuir mais significativamente para a resistência dos materiais das margens de rios de porte menor que o Rio Claro e de cabeceiras de mananciais hídricos, havendo necessidade da continuidade de estudos dessa natureza para confirmação.

\section{Considerações Finais}

As taxas de erosão das margens côncavas dos meandros do baixo Rio Claro, determinadas neste artigo, podem ser consideradas elevadas quando comparadas a estudos similares, como de Hooke (1980), Bartley et al. (2006), Souza e Cunha (2007), Constantine et al. (2009) e Dias (2012). Estas taxas de erosão são condizentes a migração lateral acentuada daqueles meandros, demonstrada por Castro et al. (2014). Deve-se considerar ainda que a cheia, as cotas e a variabilidade das vazões do baixo Rio Claro para o período estudado (2013-2014) foram abaixo da média para os últimos 10 anos. Isso significa que as taxas de erosão podem alcançar valores ainda maiores quando ocorrem as vazões máximas históricas.

Os resultados demonstram que, em curvas meândricas, as taxas mais elevadas de erosão marginal ocorrem próximas ao eixo do meandro, onde o fluxo da corrente fluvial produz impacto hidráulico, velocidades e turbulências maiores. Isso vai ao encontro com os resultados de Castro et al. (2014), que verificaram que o processo de migração lateral predominante no baixo Rio Claro foi a expansão da curva meândrica, que significa crescimento do raio de curvatura ao longo do eixo do meandro. Ou seja, o eixo permanece imóvel, enquanto o meandro migra lateralmente na direção do eixo e no sentido da margem convexa para a margem côncava. Desse modo, para a expansão do meandro ocorrer a erosão na margem côncava deve-se concentrar próxima ao eixo do meandro, como visto nas duas curvas do Rio Claro, analisadas neste artigo.

Os resultados demonstram que, seguido da influência hidráulica e hidrológica, o material constituinte das margens côncavas dos meandros é um elemento essencial para a erosão marginal e migração lateral dos meandros. Seja pela textura granulométrica, distribuição faciológica ou capacidade de desagregação (instabilidade geotécnica), o tipo de material que constitui as margens côncavas do baixo Rio Claro indicou as porções mais suscetíveis ao avanço erosivo do canal. As porções constituídas por areia média e grossa apresentaram as maiores taxas de erosão e respostas mais intensas e rápidas a desagregação sob submersão (condição similar às cheias dos rios), enquanto que as porções das margens 
constituídas por sedimentos mais finos apresentaram as menores taxas de erosão e respostas menos severas a desagregação.

Os resultados não demonstraram a influência efetiva da vegetação ciliar sobre as taxas de erosão marginal das curvas meândricas. Isso não significa que essa influência não exista. Estudos sobre ecossistemas lóticos explicam o papel inerente da vegetação ciliar, inclusive sobre as propriedades físico-químicas das águas e o transporte da carga dissolvida. As margens estudadas do Rio Claro com vegetação presente não apresentaram taxas de erosão marginal menor que as margens sem vegetação ciliar (pastagem). Observa-se que onde o fluxo da corrente fluvial atua, o impacto hidráulico erodi as margens com e sem a cobertura vegetal preservada. Estes resultados sugerem que a vegetação ciliar presente nas margens contribui pouco para refrear a erosão marginal e migração lateral de sistemas fluviais meandrantes similares ao Rio Claro ou maiores. Porém, estudos demonstraram o papel de vegetação para rios de porte menor. De qualquer maneira, se faz necessário pesquisas para ampliar o conhecimento do papel da vegetação ciliar frente a erosão marginal em diferentes rios meandrantes.

\section{Agradecimentos}

Agradecemos à Fundação de Amparo à Pesquisa do Estado de Goiás (FAPEG - Edital Univeral, Chamada Pública 005/2012) pelo auxílio financeiro ao projeto de pesquisa (processo n. 201210267000897) e à Coordenação de Aperfeiçoamento de Pessoal de Nível Superior (CAPES) pela concessão de bolsa de pós-graduação, os quais tornaram possível o desenvolvimento deste trabalho.

\section{Referências Bibliográficas}

ANA, Agência Nacional das Águas (Brasil). Hidroweb: sistemas de informações hidrológicas. Disponível em: $<$ http://hidroweb. ana.gov.br/>. Acesso em 10 de maio de 2018.

AQUINO, S.; LATRUBESSE, E. M.; SOUZA FILHO, E. E. Relações entre o regime hidrológico e os ecossistemas aquáticos da planície aluvial do rio Araguaia. Acta Scientiarum. Biological Sciences, v. 30, n. 4, p. 361-369, 28 nov. 2008. DOI: 10.4025/actascibiolsci.v30i4.5866

BARTLEY, R.; KEEN, R.; HAWDON, A.; DISHER, M.; KINSEY-HENDERSON, A.; HAIRSINE, P. Measuring rates of bank erosion and channel change in northern Australia: a case study from the Daintree River catchment. 43/06 ed. Reef and Rainforest CRC: CSIRO Land and Water Science Report, p. 51, 2006

BINDA, A.L.; FERNANDEZ, O.V.Q. Morfologia do leito e processos erosivos-deposicionais em áreas afetadas por acumulações de detritos lenhosos: Rio Guabiroba, Guarapuava/ PR. Revista Brasileira de Geomorfologia, v. 12, n. 2, p. 105115, 2011. DOI: 10.20502/rgb.v12i2.239

CAPELLO, S. V. Modeling Channel Erosion in Cohesive Streams of the Blackland Prairie, Texas at the Watershed Scale. Thesis (Master of Science). Departament of Geology, Baylor University, Texas. 2008. 67p.

CASCO, S. L.; BASTERRA DE CHIOZZI, N. I.; NEIFF, J. J. La vegetación como indicador de la geomorfologia fluvial. Revista Brasileira de Geomorfologia, v. 6, n. 1, p. 123-136, 2005. DOI: $10.20502 /$ rgb.v6i1.46

CASTRO, W. S.; DE-CAMPOS, A.; ZANCOPÉ, M.H.C. Migração do Canal na Planície Fluvial do Rio Claro - Bacia do Rio Araguaia, Goiás, Brasil. Revista Geonorte, v. 5, n. 20, p. 343-349, 2014.

CHRISTOFOLETTI, A. Geomorfologia fluvial: o canal fluvial. São Paulo: Edgard Blücher, 1981.

COFFMAN, D. K. Streambank Erosion Assessment in Noncohesive Channels Using Erosion Pins and Submerged Jet Testing, Dallas/Fort Worth, Texas. Thesis (Master of Science). Departament of Geology, Baylor University, Texas. 2009. 67p.

CONSTANTINE, J. A.; DUNNE, T. Meander cutoff and the controls on the production of oxbow lakes. Geology, v. 36, n. 1, p. 23, 2008. DOI: 10.1130/G24130A.1

CONSTANTINE, C. R.; DUNNE, T.; HANSON, G. J. Examining the physical meaning of the bank erosion coefficient used in meander migration modeling. Geomorphology, 106 (3-4), p. 242-252, 2009. DOI: 10.1016/j.geomorph.2008.11.002

CORNEY, R. K. T.; PEAKALL, J.; PARSONS, D. R.; ELLIOTT, L.; AMOS, K. J.; BEST, J. L.; KEEVIL, G. M.; INGHAM, D. B. The orientation of helical flow in curved channels. Sedimentology, v. 53, p. 249-257, 2006. DOI: 10.1111/j.13653091.2006.00771.x

DERRUAU, M. Geomorfologia. Barcelona. Ed. Ariel. p. 442, 1966.

DIAS, W. A. Dinâmica erosiva em margens plenas de canal fluvial. Dissertação (Mestrado em Geografia). Universidade Estadual de Ponta Grossa, Ponta Grossa, 2012. 102p. 
FERNANDEZ, O.V.Q. O papel de grandes detritos lenhosos na morfologia e sedimentologia no Córrego Guavirá, Marechal Cândido Rondon (PR). Geografia, Rio Claro, v. 29, n. 2, p. 229-240, 2004.

HOOKE, J. M. Magnitude and distribution of rates of river bank erosion. Earth Surface Processes and Landforms, [s.1.], v. 5, n. 2, p. 143-157, 1980. DOI: 10.1002/esp.3760050205

HOLMGREN, G. G. S; FLANAGAN, C. P. Factors affecting spontaneous dispersion of soil materials as evidenced by the crumb test: related piping and erosion in geotechnical projects. ASTM Special Technical Publication, New York, n. 623, p. 218-239, 1977.

HICKIN, E. J.; NANSON, G. C. The Character of Channel Migration on the Beatton River, Northeast British Columbia, Canada. Geological Society of America Bulletin, v. 86, n. 4, p. 487-494, 1975. DOI: 10.1130/0016-7606(1975)86

HICKIN, E. J.; NANSON, G. C. Lateral migration rates of rivers bends. Journal of Hydraulic Engineering, v. 110, n. 11 p. $1557-1567,1984$. https://doi.org/10.1061/(ASCE)07339429(1984)110:11(1557)

HUHMANN, M.; KREMENETSKI, K.V.; HILLER, A.; BRÜCKNER, H. Late quaternary landscape evolution of the upper Dnister valley, western Ukraine. Palaeogeography, Palaeoclimatology, Palaeoecology, n. 209, p. 51-71, 2004. DOI: 10.1016/j.palaeo.2004.02.014

INMET, Instituto Nacional de Meteorologia. BDMEP - Banco de Dados Meteorológicos para Ensino e Pesquisa. Disponível em: <http://www.inmet.gov.br >. Acesso em 10 de maio de 2018.

JEFFRIES, R.; DARBY, S.E.; SEAR, D.A. The influence of vegetation and organic debris on flood-plain sediment dynamics: case study of a low-order stream in the New Forest, England. Geomorphology, v. 51, n. 1-3, p. 61-80, 2003. DOI: 10.1016/ S0169-555X(02)00325-2

KNIGHTON, D. Fluvial forms and process. London: E. Arnold, 1984. 400p.

LATRUBESSE, E.M.; STEVAUX, J.C.; SANTOS, M.L.; ASSINE, M.L. Grandes sistemas fluviais: geologia, geomorfologia, paleohidrologia. In SOUZA, C.R.G.; SUGUIO, K.; OLIVEIRA, A.M.S.; OLIVEIRA, P.E. (ed.) Quaternário do Brasil. Ribeirão Preto: Holos, p. 276-297, 2005.

LEOPOLD, L. B.; WOLMAN, M. G. River channel patterns. In: DURY, G. H. (ed.) Rivers and river terraces. London: Macmillan, cap. 7, p. 197-236, 1970.

MIALL, A. D. The geology of fluvial deposits: Sedimentary
Facies, Basin Analysis and Petroleum Geology. Berlim: Springer Verlag, 1996. 582p.

MICHELI, E. R; KIRCHNER, J. W.; LARSEN, E. W. Quantifying the Effect of Riparian Forest Versus Agricultural Vegetation on River Meander Migration Rate, Central Sacramento River, California, USA. River Research and Applications, n. 20, p. 537-548, 2004. DOI: 10.1002/rra.756

MONTGOMERY, D.R.; PIÉGAY, H. Wood in rivers: interactions with channel morphology and processes. Geomorphology, v. 51, n. 1-2, p. 01-05, 2003. DOI: 10.1016/S0169-555X(02)00322-7

NANSON, G.C. Point bar and floodplain formation of the meandering Beatton River, northeastern British Columbia, Canada. Sedimentology, v. 27, p. 3-29, 1980. DOI: 10.1111/ j.1365-3091.1980.tb01155.x

NANSON, G. C.; CROKE, J. C. A genetic classification of floodplains. Geomorphology, v. 4, n. 6, p. 459-486, 1992. DOI: 10.1016/0169-555X(92)90039-Q

OLLERO, A. Channel changes and floodplain management in the meandering middle Ebro River, Spain. Geomorphology, v. 117, n. 3-4, p. 247-260, 2010. DOI: 10.1016/j.geomorph.2009.01.01

PERUCCA, E.; CAMPOREALE, C.; RIDOLFI, L. Significance of the riparian vegetation dynamics on meandering river morphodynamics. Water Resources Research, [s.1.], v. 43, n. 3, p. 1-10, 2007. DOI:10.1029/2006WR005234

SANTOS, R. M. M. Caracterização Geotécnica e Análise do Processo Evolutivo das Erosões no Município de Goiânia. Dissertação (Mestrado em Geotecnia), Departamento de Engenharia Civil, Universidade de Brasília, Brasília. 1997. 138p.

SOUZA, C. A; CUNHA, S. B. Pantanal de Cáceres - MT: Dinâmica das Margens do Rio Paraguai entre a Cidade de Cáceres e a Estação Ecológica da Ilha de Taiamã -MT. REAGB - Seção Três Lagos, v. 1, n.5, p.18-43, 2007.

STEVAUX, J.C.; LATRUBESSE, E.M. Geomorfologia fluvial. São Paulo: Oficina de textos, 2017. 320p.

SCHUMM, S. A. Evolution and Response of the Fluvial System, Sedimentologic Implications. In ETHRIDGE, F.; FLORES, R. Depositional Environments: Models for Exploration. SEPM, Society for Sedimentary Geology, Special Publication: p 19-29, 1981.

VALENTE, C. R.; LATRUBESSE, E. M.; FERREIRA, L. G. Relationships among vegetation, geomorphology and hydrology in the Bananal Island tropical wetlands, Araguaia River basin, Central Brazil. Journal of South American Earth Sciences, [s.1.], v. 46, p. 150-160, 2013. DOI: 10.1016/j. 
Castro W. S. et al.

jsames.2012.12.003

WILLIAMS, G. P. River meanders and channel size. Journal of Hydrology, v. 88, p. 147-164, 1986.

WENTWORTH, C. K. A Scale of Grade and Class Terms for Clastic Sediments. The Journal of Geology, v. 30, n. 5, p. 377-392, 1922.
ZAIMES, G.N, SCHULTZ, R.C. ISENHART, T.M. MICKELSON, S.K. KOVAR, J.L. RUSSELL, J.R. POWERS, W.P. Stream bank erosion under different riparian land-use practices in northeast Iowa. In The 9th North American Agroforestry Conference Proceedings. St. Paul, Minnesota, 2005, Anais..., 2005, p. 12-15 